\title{
In-plane anisotropy and tensile deformation behaviour of aluminium alloy AA 2014 forge plates
}

\author{
G NARENDER $^{1, *}$, E RAMJEE $^{2}$ and N ESWARA PRASAD ${ }^{3}$ \\ ${ }^{1}$ Department of Mechanical Engineering, Vignan Institute of Technology and Science, Hyderabad 508284, India \\ ${ }^{2}$ Department of Mechanical Engineering, JNTUH College of Engineering, Jawaharlal Nehru Technological \\ University, Hyderabad 500085, India \\ ${ }^{3}$ Defence Materials and Stores R\&D Establishment (DMSRDE), Defence Research and Development \\ Organisation, Kanpur 208013, India \\ e-mail: narenderr_g@yahoo.co.in
}

MS received 9 July 2017; revised 31 October 2017; accepted 8 August 2018; published online 8 January 2019

\begin{abstract}
Plastic flow behaviour and fracture mechanism of aluminium alloy AA 2014 forged plates under tensile loading conditions are investigated and the results obtained are presented and discussed in the present study. The effects of heat treatment (namely, solution treatment and artificial ageing) on micro-structural homogeneity, tensile behaviour and nature of fracture were studied using hardness, tensile, optical and scanning electron microscopy methods. Experimental engineering stress-engineering strain and true stress-true strain data of the aluminium alloy AA 2014 in different ageing conditions have been analysed using Hollomon, Ludwik and Ludwigson plastic flow relationships. The alloy is found to exhibit moderate degree of in-plane anisotropy and anisotropic index. Further, the alloy in both solution-treated and aged conditions exhibits three different stages of strain-hardening rate and the highest strain-hardening rate occurs at regions of lower strain both in solution-treated and peak-aged conditions. It is also observed that the longitudinal specimen ( $\mathrm{L}$ parallel to forging direction) exhibits higher strain hardening, while the specimen with $\mathrm{T}$ orientation exhibits lowest strain-hardening rates both in solution-treated and aged conditions. The alloy under study in all the heat treatment conditions exhibits ductile fracture mechanism with higher density of uniformly distributed macro- and micro-dimples.
\end{abstract}

Keywords. Aluminium alloy AA 2014; in-plane anisotropy; strain hardening; fracture mechanism; anisotropic index; plastic flow.

\section{Introduction}

Aluminium alloys have become important materials for space, military, automobile and various commercial applications due to their higher specific strength, low density and specific modulus apart from adequate fracture and fatigue resistance. A few attempts have been made in the past to study deformation behaviour of aluminium alloys for sheet metal applications [1-3]. Earlier studies also reported formability characteristics and forming limits of the AA 2014 automotive aluminium sheets [4, 5]. In-plane anisotropy in various mechanical properties was also reported, thus establishing the anisotropy with texture and yield locus [6-15]. However, the anisotropy with work-hardening behaviour is not reported to date in case of the AA 2014 alloy forged products. Hence, the present work aims at studying the in-plane anisotropy and work-hardening behaviour of forged aluminium alloy AA 2014 in solutiontreated and peak-aged conditions. A model constituting

*For correspondence plastic anisotropy is fitted with the data of uniaxial tensile deformation. Finally the effects of ageing on the plastic flow and in-plane anisotropy, work-hardening behaviour and fracture mechanism of aluminium alloy AA 2014 are evaluated, analysed and reported in the present work.

\section{Experimental}

\subsection{Material details}

The material taken for the investigation is aluminium alloy AA 2014, which is an Al-Cu-Mg-Si alloy. The forged AA 2014 block in the present investigation was procured from Mishra Dhatu Nigam (MIDHANI), Hyderabad, India. The nominal composition of the alloy forging, given in table 1, was found to be well within the specified range of the standard composition of aluminium alloy AA 2014.

Copper is one of the most important alloying element for aluminium, because of its appreciable solubility and strengthening effect. Many commercial alloys contain copper, 
Table 1. Chemical composition of solutionised aluminium alloy AA 2014.

\begin{tabular}{lcccccc}
\hline Element & $\mathrm{Cu}$ & $\mathrm{Si}$ & $\mathrm{Mn}$ & $\mathrm{Mg}$ & $\mathrm{Fe}$ & $\mathrm{Al}$ \\
\hline Weight $(\%)$ & 4.4 & 0.8 & 0.8 & 0.4 & - & Remainder \\
\hline
\end{tabular}

either as the major addition or among the principal alloying element. These binary aluminium-copper alloys are used as master alloys for making of more complex alloys. In these alloys, higher strengths have been achieved because the relatively high silicon content thus increases the response to hardening on artificial ageing. This alloy is particularly well suited for parts and structures requiring high strength to weight ratio and are commonly used to make aircraft and truck wheels, aircraft wing skins, structural parts and those parts requiring good strength at temperatures up to $150^{\circ} \mathrm{C}$. This alloy has good machinability but has limited weldability.

\subsection{Tensile testing}

Required number of specimens of size $170 \mathrm{~mm} \times 105$ $\mathrm{mm} \times 4 \mathrm{~mm}$ for testing were made using an EDM wire cut machine; subsequently they were solutionised and aged. Orientation of tensile specimens cut from these plates obtained from the forged is block shown in figure 1 .

All the specimens were solutionised at $502 \pm 5^{\circ} \mathrm{C}$ for 55 min and quenched in hot water of $64^{\circ} \mathrm{C}$ in order to avoid warpage and distortion. Different specimens were separately aged at $177 \pm 3^{\circ} \mathrm{C}$ in the furnace for 2,10 and $20 \mathrm{~h}$, which were designated as under-aged, peak-aged and overaged heat treatment conditions, respectively.

The tensile test specimens were cut from the heat-treated plates along three directions $\mathrm{L}, \mathrm{L}+45^{\circ}$ and $\mathrm{T}$ as shown in figure 2. Tensile tests at room temperature were conducted on an INSTRON 5500R-4507-250 kN universal testing machine at $1 \mathrm{~mm} / \mathrm{min}$ crosshead speed. The strain was recorded using an axial extensometer.

Microstructure of the specimens is studied using a microscope (Neophot). The emery-polished specimens were final polished using alumina paste, followed by etching. The etchant used was Keller's reagent, consisting of $1 \mathrm{ml} \mathrm{HF}, 3 \mathrm{ml} \mathrm{HNO}_{3}, 3 \mathrm{ml} \mathrm{HCl}$ and $93 \mathrm{ml} \mathrm{H}_{2} \mathrm{O}$.

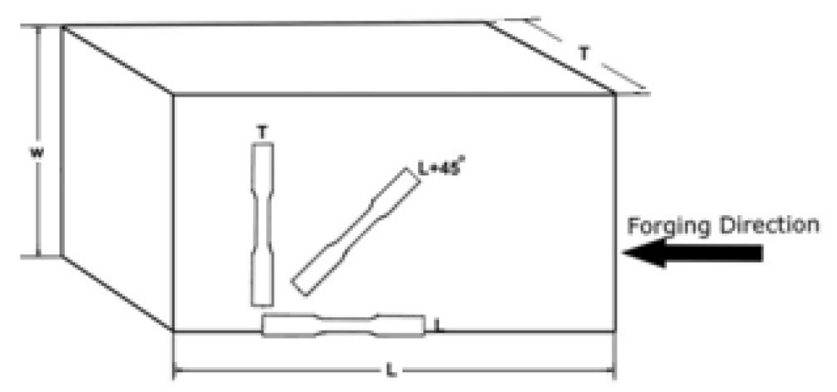

Figure 1. Orientation of tensile specimens cut from forged block.
Tensile tests were conducted on specimens of solutiontreated and aged conditions. The ASTM-recommended E-8 specimens (ASTM Standard E-8, 2013), shown in figure 2, were used for tensile testing [16]. Two specimens were tested in each sample direction and the average values of $0.2 \%$ of yield strength $\left(\sigma_{Y}\right)$, ultimate tensile strength $\left(\sigma_{U T S}\right)$, percentage elongation and percentage reduction in area were calculated.

\section{Results}

\subsection{Microstructure}

The optical micrographs of grain structure after etching with Keller's etchant are shown as a Pseudo-3D image in figure 3 .

The alloy under study contains fine insoluble dispersoids $(\mathrm{MnFe})_{3} \mathrm{SiAl}_{12}, \mathrm{Cu}_{2} \mathrm{Mn}_{3} \mathrm{Al}_{20}$ and $\mathrm{Mn}_{3} \mathrm{SiAl}_{12}$, and soluble ternary phase particles are distributed throughout the matrix in the structure. The fine grain structure of elongated shape in the direction of forging, which is the result of forging in hot condition, also helps in the improved mechanical properties. The alloy exhibits completely re-crystallised microstructure with equiaxed grains in all three planes. This is due to complete re-crystallisation during solution treatment.

\subsection{Tensile properties and in-plane anisotropy}

Figure 4 shows engineering stress-engineering strain diagram up to breaking stress of the alloy under study in solution-treated condition, solution-treated and under-aged condition (ST $+450 \mathrm{~K} / 2 \mathrm{~h})$, solution-treated and peakaged condition $(\mathrm{ST}+450 \mathrm{~K} / 10 \mathrm{~h})$ and solution-treated and overaged condition ( $\mathrm{ST}+450 \mathrm{~K} / 20 \mathrm{~h})$.

The material exhibits variations in yield strength $\left(\sigma_{Y}\right)$, ultimate tensile strength $\left(\sigma_{U T S}\right)$, percentage elongation and percentage reduction of area in different test directions. The values of $\sigma_{Y}$ and $\sigma_{U T S}$ are found to be maximum along $\mathrm{T}$ direction and minimum in $\mathrm{L}+45^{\circ}$ directions in solutiontreated condition (see the data in table 2 and figure 5).

It has been reported that the elongation and yield strength are the most sensitive in-plane anisotropic tensile properties, even in crystallographically symmetric FCC metals, such as Al, Al-Li and Nimonic alloys, and such unexpected in-plane anisotropy can be attributed to strong crystallographic texture and grain fibering [6-15, 17-21]. The Nimonic C-263 alloy, exhibits the highest and lowest values of $\sigma_{Y}$ in $\mathrm{L}$ and $\mathrm{T}$ directions in cold rolled and solutiontreated condition [2-4]. On the other hand, it has been reported that $\mathrm{Al}-\mathrm{Li}$ alloys exhibit lower value of $\sigma_{Y}$ in $45^{\circ}$ $60^{\circ}$ direction as compared with $\mathrm{L}$ and $\mathrm{T}$ directions [9-14] and recently Mehta et al [15] reported in case of cold-rolled and solution-annealed Ni-based hastelloy C-276 alloy that 


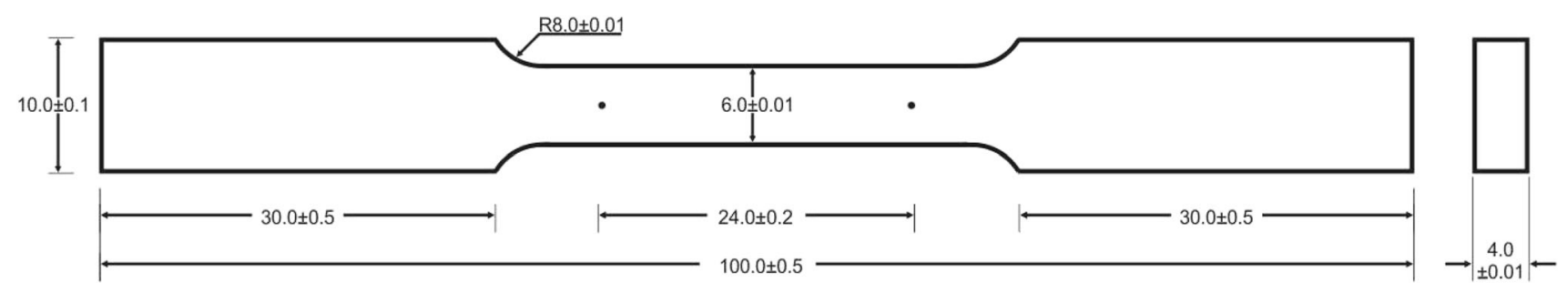

Figure 2. Schematic diagram of tensile specimen (all dimensions are in $\mathrm{mm}$ ).

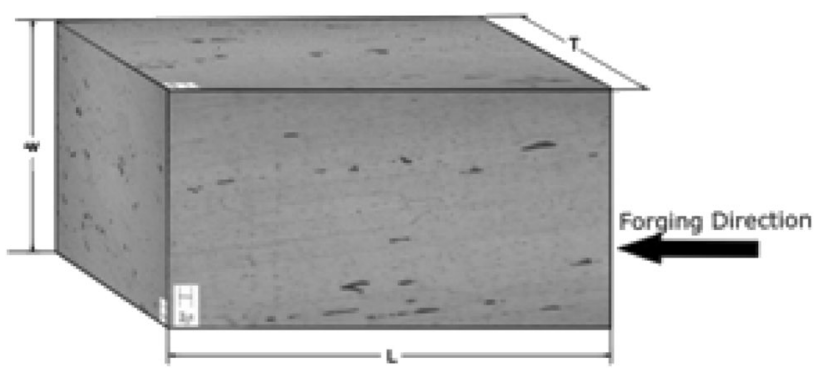

Figure 3. Pseudo-3D image showing the microstructure of alloy forged plate.

the highest and lowest values of $\sigma_{\mathrm{Y}}$ are in $\mathrm{L}+45^{\circ}$ and $\mathrm{L}$ directions, respectively (with elongation exhibiting opposite trend to that of $\sigma_{\mathrm{Y}}$ ). Although ageing does not appear to change the macroscopic flow behaviour, it causes remarkable variations in various flow parameters and sub-structural changes.

Figure 6 shows the data of true stress-true strain of the alloy under study in three test directions. There is continuous work hardening up to $\sigma_{U T S}$ in all specimen directions and it can be observed by the nature of engineering stressengineering strain and true stress-true strain curves obtained for the specimen. True stress-true strain graph trends are similar to those of engineering stress-engineering strain graphs. The true stress-true strain data do not reveal any further information for analysis on the in-plane anisotropy. However, these data are essential for the analysis of plastic flow behaviour of the alloy, and this aspect is elaborated in the following section. The variation of percentage elongation, $\sigma_{U T S}$ and $\sigma_{Y}$ with the angle with forging direction is shown in figure 7 , which clearly indicates the anisotropy of material under study.

\subsection{Fracture behaviour}

The fractured surfaces of the specimens of tensile test were observed in a scanning electron microscope to determine the mode of fracture. The fracture features of the aluminium alloy in the two heat-treated conditions (solution treated and peak aged) are shown in figures 8 and 9 at low any high magnifications, respectively. The fractographs in figure 8 show fibrous fracture surface associated with elongated grains also involving failure at grain boundaries of solution-treated specimens. The fractographs at higher magnifications (figure 9) clearly show that the alloy plates under tensile loading fail predominantly by high-energy ductile dimple fracture with a smaller extent of shear fracture. The dimples observed were found to be distinctly of two different sizes. The average diameter of coarse dimples is $2-5 \mu \mathrm{m}$ and their number density as well as size decrease initially as the orientation changes from $0^{\circ}$ to $45^{\circ}$ and then increases again. On the other hand, the fine microdimples are uniformly distributed and can be seen clearly. The two different size distributions of dimples (fine/microdimples and coarse) lead to gross dimple fracture. This can be attributed to the coalescence, void nucleation and growth. The void nucleation particles presumably are largesized insoluble dispersoids $(\mathrm{MnFe})_{3} \mathrm{SiAl}_{12}, \mathrm{Cu}_{2} \mathrm{Mn}_{3} \mathrm{Al}_{20}$ and $\mathrm{Mn}_{3} \mathrm{SiAl}_{12}$ in case of coarse dimples (whose density and spacial distribution match well with those of the dispersoids) and $\gamma^{\prime}$ precipitates in case of the fine and uniformly distributed micro-dimples. The observations are similar for all other conditions, i.e., ST $+10 \mathrm{~h}$ (peak-aged) aged conditions.

\section{Discussion}

\subsection{Tensile flow behaviour}

Ludwigson has modified the Ludwik relation to explain the plastic behaviour of materials. The modified relation given by Ludwigson is

$$
\sigma=k_{1} * \varepsilon_{p}^{n 1}+\exp \left(k_{2}+\varepsilon_{p} * n_{2}\right)
$$

where $\sigma$ is true stress, $k_{1}$ is strength coefficient, $\varepsilon_{p}$ is true plastic strain, $n_{1}$ is work-hardening coefficient, $k_{2}$ and $n_{2}$ have the same significance as $k_{1}$ and $n_{1}$ and $k_{1} * \varepsilon_{p}^{n 1}$ constituent of the term relates the positive departure of flow curve at low strains from the Ludwik relation and it describes flow curve at higher strains (see the data in figure 10). The flow curve parameters of the alloy in different sample directions have been derived using the Hollomon, Ludwik and Ludwigson relations [22]. The details of these constitutive equations are included in tables 2 and 3, 

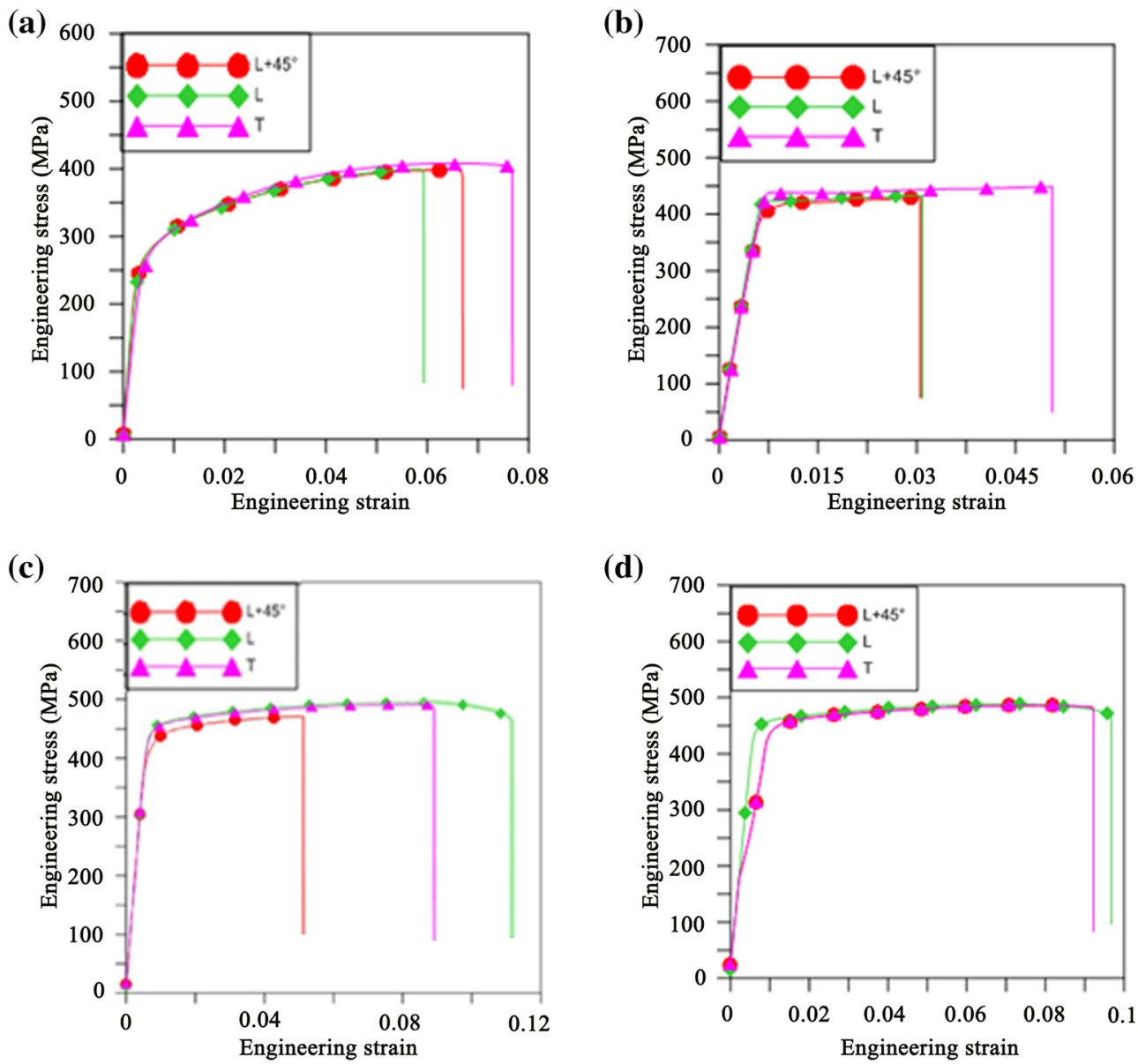

Figure 4. Engineering stress-engineering strain diagram up to breaking stress of aluminium alloy AA 2014 in (a) solution-treated condition, (b) under-aged condition ( $\mathrm{ST}+450 \mathrm{~K} / 2 \mathrm{~h})$, (c) peak-aged condition $(\mathrm{ST}+450 \mathrm{~K} / 10 \mathrm{~h})$ and (d) overaged condition $(\mathrm{ST}+450 \mathrm{~K} / 20 \mathrm{~h})\left(\right.$ all tests were conducted at room temperature in laboratory air atmosphere at a strain rate of $\left.10^{-4} \mathrm{~s}^{-1}\right)$.

Table 2. Anisotropy in tensile properties of aluminium alloy AA 2014 plate in solution-treated condition.

\begin{tabular}{|c|c|c|c|c|}
\hline \multirow[b]{2}{*}{ S1. no. } & \multirow[b]{2}{*}{ Property } & \multicolumn{3}{|c|}{ Specimen orientation with respect to the forging direction $\left(^{\circ}\right)$} \\
\hline & & $\mathrm{L}$ & $\mathrm{L}+45^{\circ}$ & $\mathrm{T}$ \\
\hline 1 & $0.2 \%$ Y.S. (MPa) & 277.1 & 276.3 & 281.8 \\
\hline 2 & UTS (MPa) & 399.6 & 398.7 & 408.7 \\
\hline 3 & Total elongation $(\%)(25 \mathrm{~mm}$ gauge length) & 19.6 & 20.7 & 18.4 \\
\hline 4 & Work-hardening exponent $n$ & 0.13614 & 0.13704 & 0.18217 \\
\hline 5 & $\sigma_{U T S /} \sigma_{Y}$ & 1.442 & 1.443 & 1.450 \\
\hline 6 & $\begin{array}{l}\text { Hollomon equation } \\
\sigma=k * \varepsilon_{p}^{n}, k \text { in } \mathrm{MPa}\end{array}$ & $\begin{array}{c}k=525.75 \\
n=0.13614\end{array}$ & $\begin{array}{c}k=532.65 \\
n=0.13704\end{array}$ & $\begin{array}{c}k=526.77 \\
n=0.18217\end{array}$ \\
\hline 7 & $\begin{array}{c}\text { Ludwik equation } \\
\sigma=\sigma_{0}+k_{1} * \varepsilon_{p}^{n 1} \\
\sigma_{0} \text { and } k_{1} \text { in } \mathrm{MPa}\end{array}$ & $\begin{array}{c}\sigma_{0}=211.39 \\
k_{1}=230.93 \\
n_{1}=0.39112\end{array}$ & $\begin{array}{c}\sigma_{0}=149.25 \\
k_{1}=249.75 \\
n_{1}=0.23577\end{array}$ & $\begin{array}{c}\sigma_{0}=204.60 \\
k_{1}=203.78 \\
n_{1}=0.36111\end{array}$ \\
\hline 8 & $\begin{array}{c}\text { Ludwigson equation } \\
\sigma=k_{1} * \varepsilon_{p}^{n 1}+\exp \left(k_{2}+\varepsilon_{p} * n_{2}\right) \\
k_{1} \text { and } k_{2} \text { in } \mathrm{MPa}\end{array}$ & $\begin{array}{c}k_{1}=563.2 \\
n_{1}=0.13245 \\
k_{2}=3.14205 \\
n_{2}=-90.3\end{array}$ & $\begin{array}{c}k_{1}=573.4 \\
n_{1}=0.14487 \\
k_{2}=3.59785 \\
n_{2}=-41.24\end{array}$ & $\begin{aligned} k_{1} & =596.7 \\
n_{1} & =0.1567 \\
k_{2} & =3.6267 \\
n_{2} & =-83.46\end{aligned}$ \\
\hline
\end{tabular}

Tests were conducted at room temp at an initial strain rate of $10^{-4} \mathrm{~s}^{-1}$. 

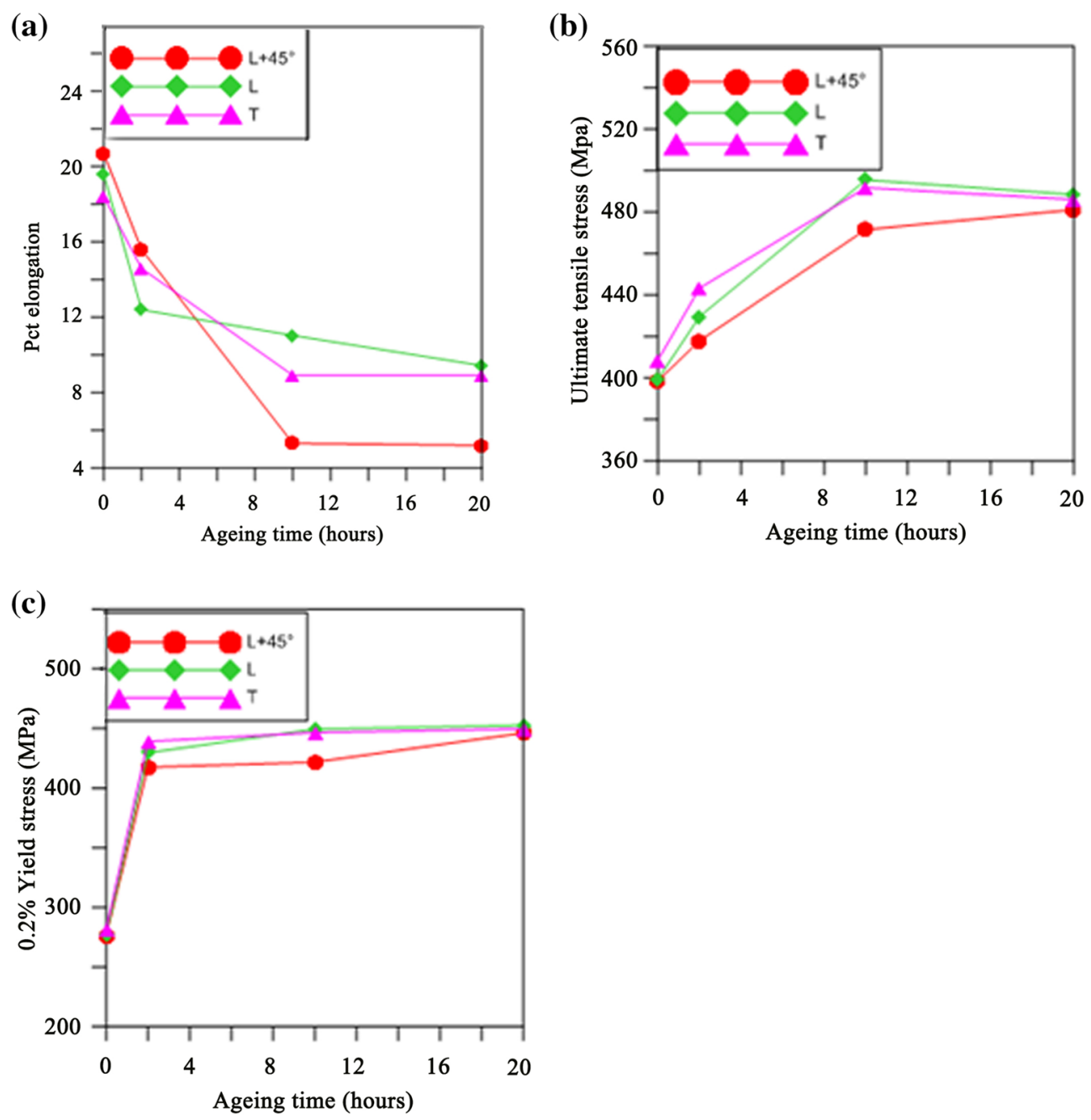

Figure 5. (a) Percentage (pct) elongation-ageing time relation, (b) ultimate tensile stress-ageing time relation and (c) $0.2 \%$ yield stress-ageing time relation of aluminium alloy AA 2014.

respectively, for the two heat treatment conditions of solution treated and peak aged. The constitutive equation parameters values and their corresponding errors are given in table 4 . The data in table 4 clearly indicate an adequate fit of data to flow curve equation. Two slopes in flow curves have been observed in austenitic stainless steels and FCC materials with lower values of stacking fault energy (SFE) [23]. Two distinctly different mechanisms occur in lowand high-strain regimes in plastic flow of these materials with low SFE. During initial deformation the planar flow of dislocations and later, at higher strain rates, cross-slip associated with resultant cell formation take place in plastic flow.

The values of coefficient of determination $\left(R^{2}\right)$ lie in the range of $0.99474-0.99765$. It can be seen that a very large fraction of variations observed in true stress is accounted for in the flow curve fittings of Ludwigson equation and strain-hardening exponents in the regimes of lower strain [24]. The values of strain-hardening exponent $n_{1}$ of the Ludwik region is minimum and maximum in
$\mathrm{L}+45^{\circ}$ and $\mathrm{L}$ directions, respectively. Similarly $n_{2}$ values are negative and strain hardening is steeper in the Ludwigson regime.

The variation of strain-hardening rate, $\theta(=\mathrm{d} \sigma / \mathrm{d} \varepsilon)$ with (a) true plastic strain and with (b) true stress in solutiontreated as well as aged conditions is shown in figure 11 . Figure 11a and $\mathrm{b}$ shows that there are three fairly distinct regimes of strain hardening of the alloy in both solutiontreated and aged conditions. In regime I the strain-hardening rate initially decrease, in regime II it remains constant and in regime III it starts decreasing. The figures reveal that the alloy in aged condition (ST $+450 \mathrm{~K} / 2 \mathrm{~h}$ ) exhibits higher initial strain-hardening rates as compared with the alloy in solution-treated condition. However, the strainhardening rate plots merge at higher true plastic strain level and higher true stress regions for both the solution-treated and aged conditions.

The data in figures 11 and 12 reveal that the longitudinal specimen ( $\mathrm{L}$ parallel to forging direction) exhibits higher strain-hardening rates, while the specimens with $\mathrm{L}+45^{\circ}$ 

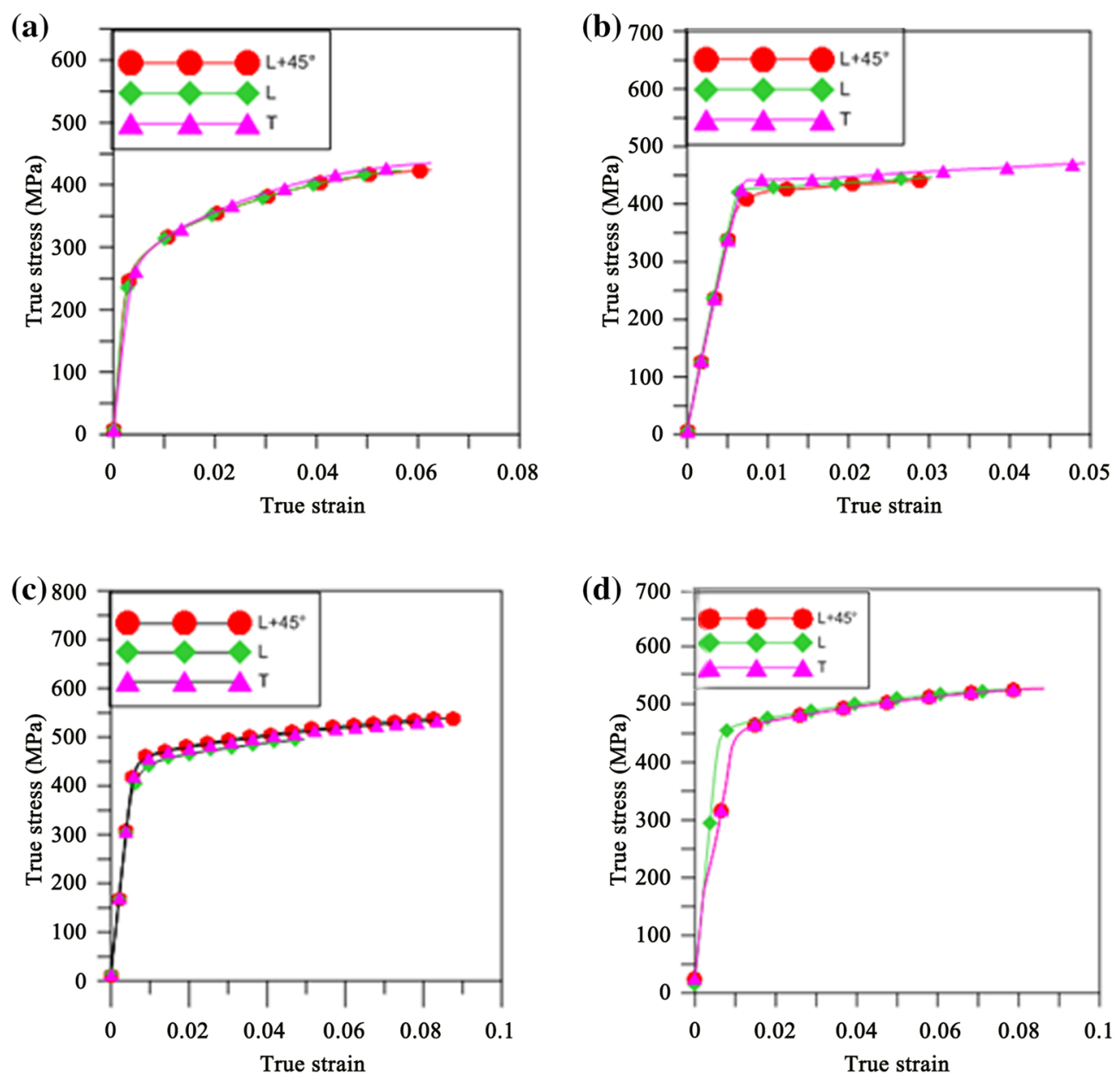

Figure 6. True stress-true strain diagram up to UTS of aluminium alloy 2014 in (a) solution-treated condition, (b) under-aged condition $(\mathrm{ST}+450 \mathrm{~K} / 2 \mathrm{~h})$, (c) peak-aged condition $(\mathrm{ST}+450 \mathrm{~K} / 10 \mathrm{~h})$ and $(\mathbf{d})$ overaged condition $(\mathrm{ST}+450 \mathrm{~K} / 20 \mathrm{~h})($ all tests were conducted at room temperature in laboratory air atmosphere at a strain rate of $10^{-4} \mathrm{~s}^{-1}$ ).

orientation exhibit lowest strain-hardening rates both in solution-treated and aged conditions. It can be interpreted that due to the sub-structural features in the low SFE alloys there is variation of work-hardening rate in the three regimes of the present alloy $[25,26]$. The decrease in strain-hardening rate is due to dynamic recovery (by crossslip and annihilation of screw components of dislocations) in regime I. Initiation of primary deformation twinning in the microstructure results in constant strain-hardening rate in regime II.

At the initial stage of regime II, the boundaries of deformation twins that begin to form behave as regions for dislocation pile-up and storage-like grain boundaries. This prevents slip propagation on each system that intersects the twins. Compared with the initial grain size, the slip distance would become much shorter. Formation of twins leads to reduction of the grain size. Overall strain-hardening rate remaining nearly constant in regime II results from steady increase of twin density with strain, which progressively decreases slip distances.
Earlier investigators suggested that there is a decreased rate of primary twin formation in regime III, which leads to the drop in strain-hardening rate [26]. In case of MP $35 \mathrm{~N}$ alloy, based on the micro-structural observations, two models were proposed for decreasing rate of production of deformation twins. The first model is related to formation of sub-grains due to the development of lattice curvature within grains. The second model is related to the formation of new twins on the primary (111) matrix plane. There is increasing misorientation at the interface of twin-primary (111) matrix plane, which has deformation twins, on which new twins form. In regime III, both models contribute to the noted difficulty of propagating latest primary twins with strain. In both models, the distance to which a twin can grow before meeting an obstacle is reduced. This results in a decrease of grain size, which makes twining harder since higher stresses are required to nucleate twins in smaller grains. The reason for fall in the strain-hardening rate in regime III beyond certain strain $(\sim 4 \%)$ is increase in twin density with strain, which results in decrease of inter-twin 

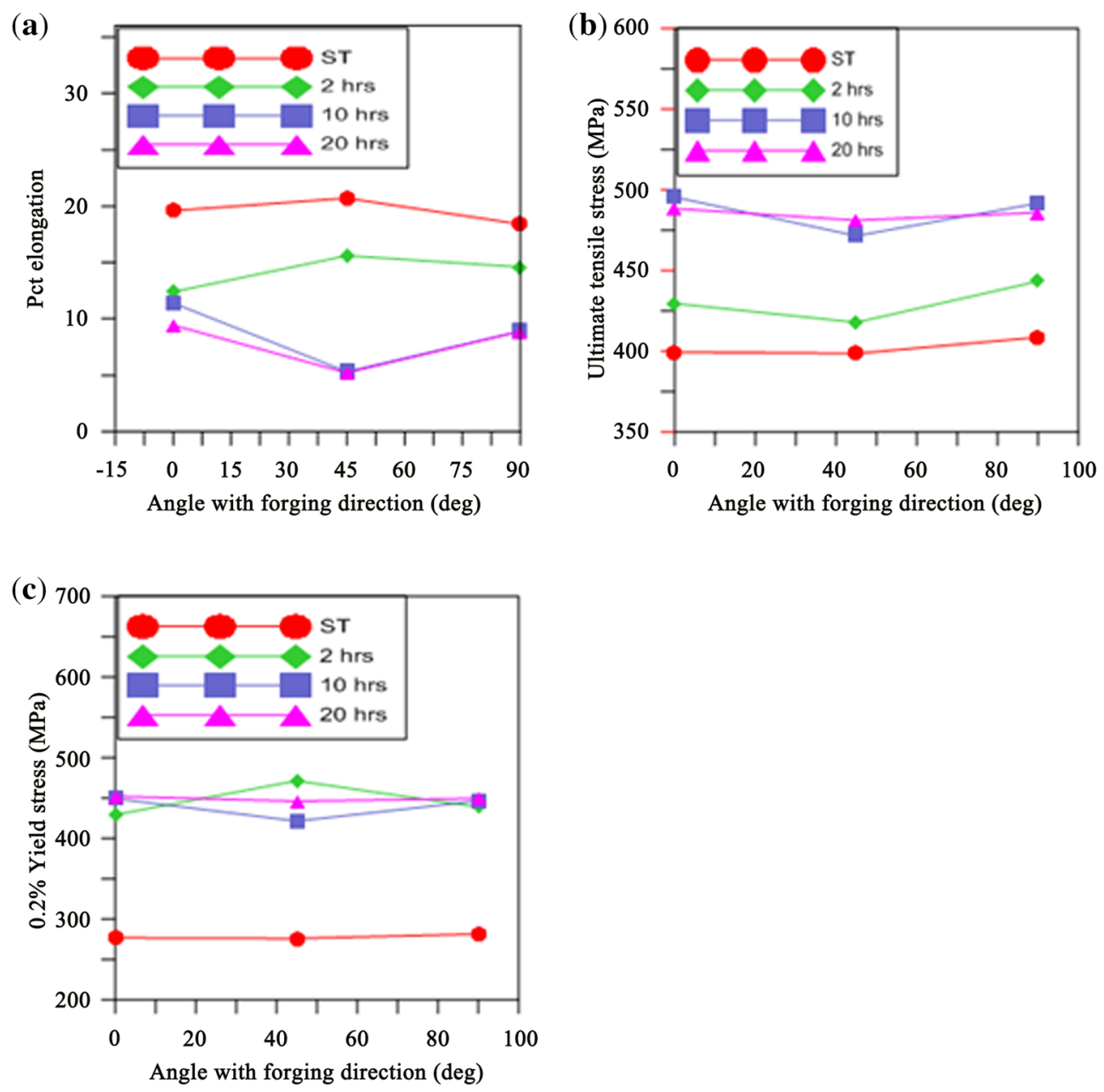

Figure 7. (a) Percentage (pct) elongation-angle with forging direction, (b) ultimate tensile stress-angle with forging direction and (c) $0.2 \%$ yield stress-angle with forging direction of aluminium alloy AA 2014 .

distance progressively. This causes further difficulty in nucleation of twinning, thereby leading to fall in strainhardening rate in regime III.

The sum of residual squares of a fit, $\chi^{2}$ values, obtained for these relationships over the complete range of fit of $\sigma-\varepsilon$ data is given in table 5. It can be concluded from the data in figure 10 that the $\log -\log$ plots of true stress-true plastic strain are linear at higher strains. This can be attributed to the applicability of the Hollowmon equation above transition strain, that is at high strains only. Over the complete range of $\sigma-\varepsilon$ data, the average line shows more deviation from the Hollomon equation. This leads to a large underestimation of values of stress at higher and very low strains, and also overestimation at intermediate stresses. This behaviour observed suggests that the Holloman equation cannot be applied over the complete range of experimental $\sigma-\varepsilon$ data. This is displayed in the very high $\chi^{2}$ values for Hollomon equation (table 5) obtained for various conditions at $450 \mathrm{~K}$. It is evident from figure $10 \mathrm{a}$ and $\mathrm{b}$ that the Ludwigson relationship contributes the best fit of the $\sigma-\varepsilon$ data for all the conditions among three plastic flow relationships (Hollomon, Ludwik and Ludwigson).
This is justified by the lowest $\chi^{2}$ values obtained for Ludwigson equation compared with those obtained for other flow relationships. Table 5 reflects that for all the conditions the Hollomon relation provides poor fit at lower strain levels for the $\sigma-\varepsilon$ data of the alloy. Furthermore, at higher strain levels, the data fit is better for Ludwik relationship but at lower strain levels the fit is poor. hence, for all the conditions studied, the Ludwigson relationship provides the best fit for the experimental data; hence, further discussion is confined to this relationship.

In the present study the important observation is that the alloy in solution-treated condition at lower strain exhibits transient flow behaviour. Such behaviour has been reported in austenitic stainless steels, silver and $\alpha$-brass, which are low-SFE-FCC materials [27]. Ludwigson reported that at the beginning stage of plastic deformation, i.e., at low strains in low-SFE materials, the transient flow is associated with planar glide that leads to cell structure formation. It causes a change in macroscopic flow behaviour over a certain value of critical strain, which is known as transient strain. Table 6 shows the details of flow parameters obtained by Ludwigson for the complete range of FCC 

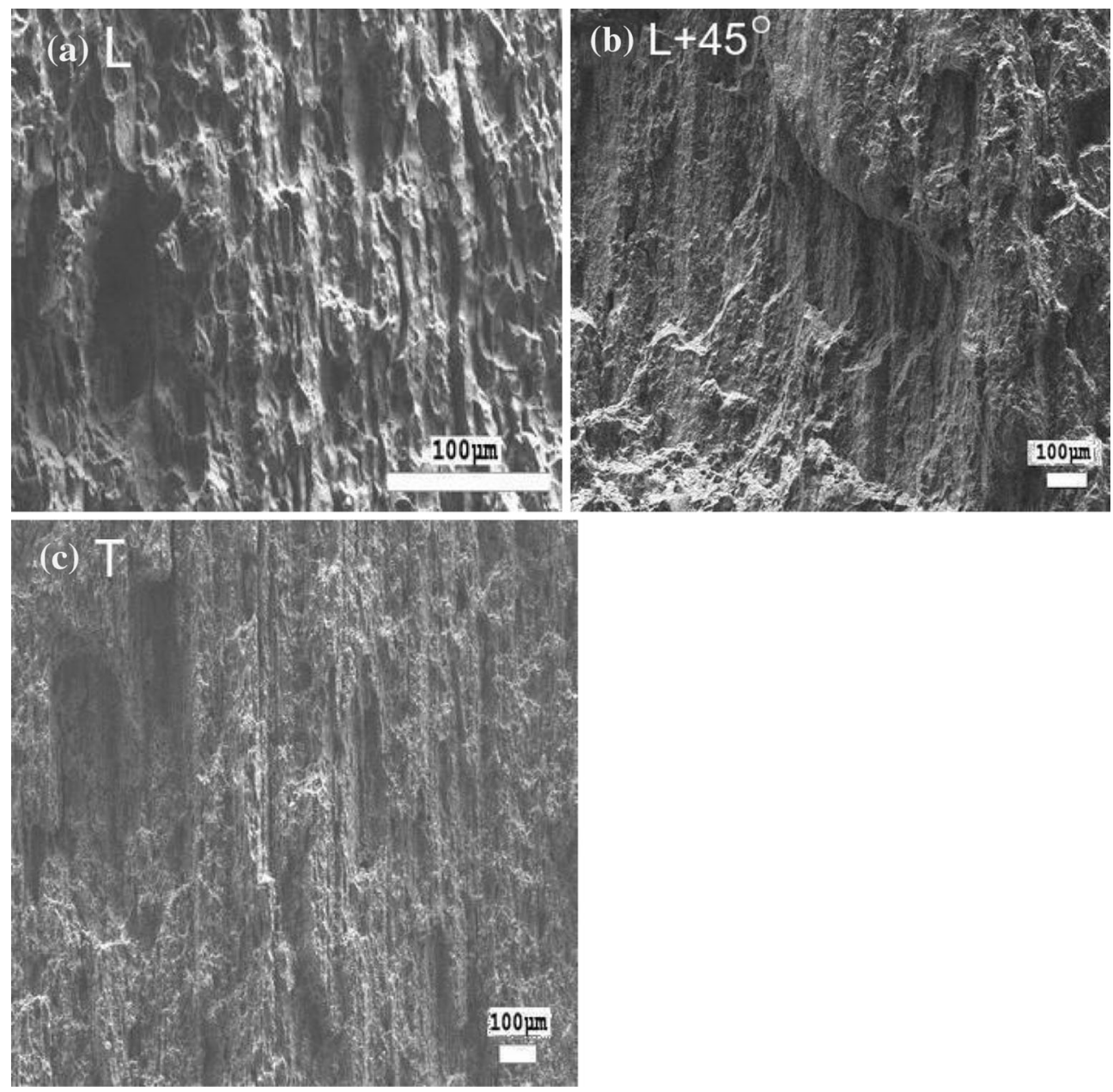

Figure 8. Low-magnification macrofractographical features of tensile-tested specimens of aluminium alloy AA 2014 in solutiontreated condition in various test directions.

materials. These materials are grouped in increasing values of SFE, with order ranging from 10 to $200 \mathrm{~mJ} \mathrm{~m}^{-2}$. The lowest SFE materials like 70-30 brass and stainless steels exhibit the largest values of transient strains $\varepsilon_{L}(8-15 \%)$ and the smallest negative values of $n_{2}$. Table 6 clearly reflects the data that aluminium alloy SFE is remarkably higher as compared with stainless steel and brass. This is the main reason for the higher negative values of $n_{2}$ for the present alloy under study. Silver and copper, which have slightly higher stalking fault energies, obey the Hollomon relation; they exhibit lower values of transient strain $\varepsilon_{L}$ (3\%) and higher negative values of $n_{2}$. In this series, nickel and aluminium have highest stalking fault energies, do not exhibit transition flow behaviour and obey the Hollomon relation. Thus, FCC materials related to low and intermediate stalking fault energies (in table 6, stainless steel to copper) generally exhibit transition in flow behaviour as shown in the true stress-true plastic strain curve [27].

Figure 13 shows the optical micrographs revealing the microstructure of the present alloy in solution-treated and aged conditions followed by tensile deformation to fracture. The density of deformation bands has been observed to be more in solution-treated alloy as compared with the alloy with aged conditions. This suggests that the alloy in solution-treated condition is subjected to substantially high level of tensile plastic deformation.

\subsection{In-plane anisotropy in the tensile properties}

Most widely used parameters to determine the anisotropy of metals are the (1) percentage in-plane anisotropy $\left(A_{I P}\right)$ $[17,21]$ and (2) anisotropy index $(\delta)[15]$ shown in Eqs. (2) and (3). Yield strength anisotropy is related to $A_{I P}$; on the other hand, the anisotropy index $(\delta)$ is associated to elongation anisotropy. The values of $A_{I P}$ and $\delta$ are zero for isotropic materials.

The percentage in-plane anisotropy $\left(A_{I P}\right)$ is given as $[17,21]$

$$
A_{I P}=\frac{2\left(\sigma_{Y S}\right)_{L+45^{\circ}}-\left[\left(\sigma_{Y S}\right)_{L}+\left(\sigma_{Y S}\right)_{T}\right]}{2\left(\sigma_{Y S}\right)_{L+45^{\circ}}}
$$

The anisotropy index $(\delta)$ is defined as [11] 

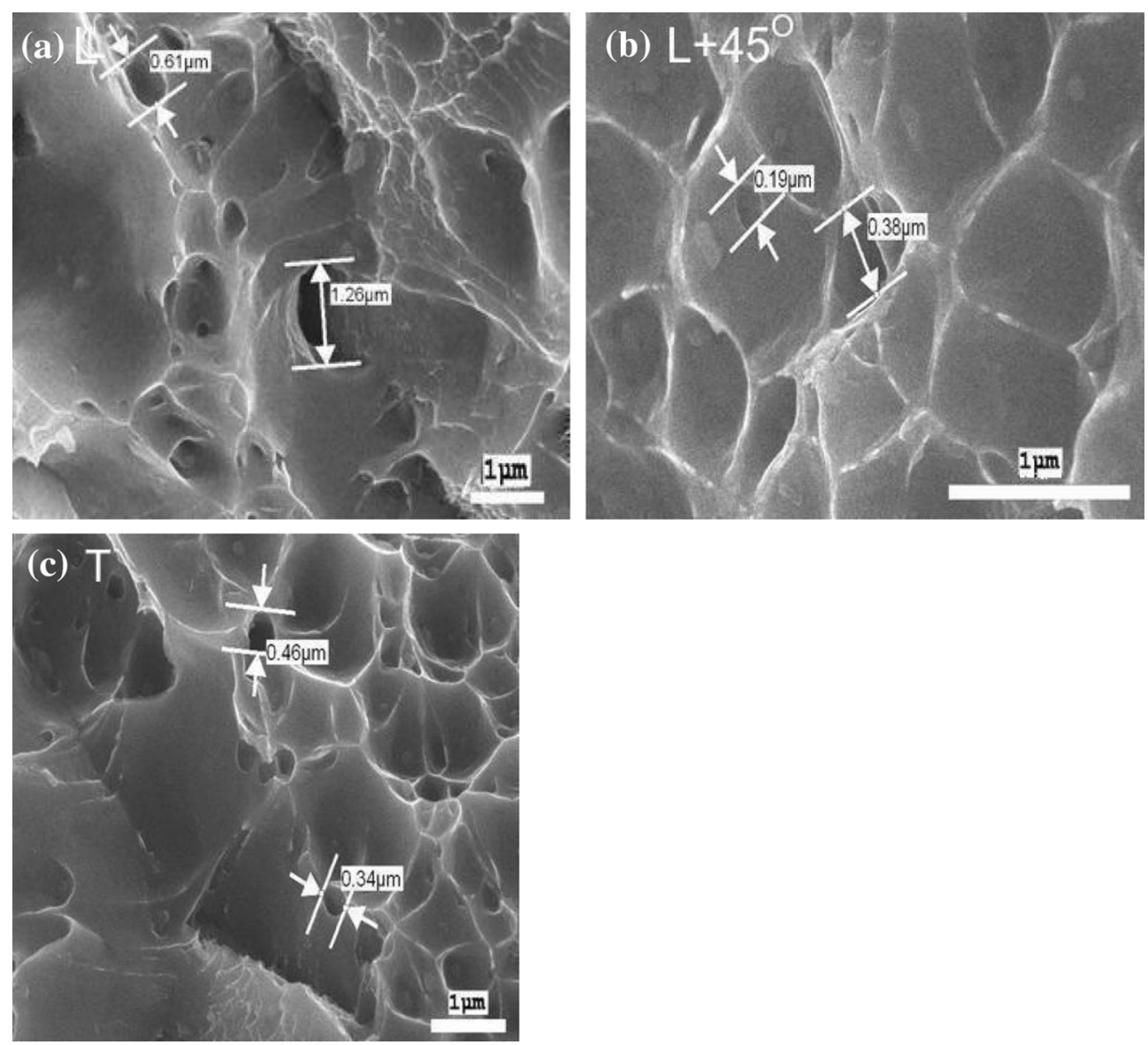

Figure 9. High-magnification macrofractographical features of tensile-tested specimens of aluminium alloy AA 2014 in solutiontreated peak-aged $(\mathrm{ST}+450 \mathrm{~K} / 10 \mathrm{~h})$ condition in various test directions.

$$
\delta=\frac{(\text { Pct.El. })_{L}-(\text { Pct.El. })_{T}}{(\text { Pct.El. })_{L}+(\text { Pct.El. })_{T}}
$$

For the alloy under study the in-plane anisotropy $\left(A_{I P}\right)$ and the anisotropic index $(\delta)$ are the highest in peak-aged $(\mathrm{ST}+450 \mathrm{~K} / 10 \mathrm{~h})$ condition and moderate in other aging conditions (see the data in table 7). In general, the alloy under study exhibits moderate values of $A_{I P}$ and $\delta$, which can be attributed to the presence of anisotropy.

The studies in the past two decades, particularly on highstrength Al-Li alloys, have shown that FCC alloy products too exhibit anisotropy in mechanical properties significantly $[9-14,18,28-31]$. The directionality in tensile properties has been attributed to (i) crystallographic texture and (ii) mechanical fibering associated with grain anisotropy, banding of small grains, degree of re-crystallisation, and directionality of fine as well as coarse inclusions, distribution and nature of strengthening precipitates. From the Schmid factors determination in Al-Li alloys as a function of orientation with respect to rolling direction it is anticipated that maximum in tensile ductility and minimum in tensile strength occur at orientations $50^{\circ}-60^{\circ}$ to the rolling directions [29]. A separate investigation on 8090 and 8091
Al-Li alloys [31] revealed similar directionality variation in tensile anisotropy by calculations using Taylor and Sachs models. By combined controlling of ageing treatment and crystallographic texture, in age-hardenable aluminium alloys the anisotropy can be tailored [32]. In another study on $\mathrm{Al}-\mathrm{Mg}-\mathrm{Si}$ alloy sheet specimen, the variation in yield strength in different ageing conditions was determined by considering grain boundary, solid solution and shearable precipitate strengthening [33].

\subsection{In-plane anisotropy in the tensile fracture behaviour}

The tensile fracture surfaces, exhibiting classic ductile features in all the three in-plane test directions, reveal significant variation in size and shape of the dimples from $\mathrm{L}$ to $\mathrm{T}$ directions (see the fractographs of figure 9). The variation in values of work-hardening coefficients $n_{1}$ and $n_{2}$ of the flow curves also confirms this observed anisotropy in the fracture behaviour of the alloy. The shape of dimples that appear is spherical in $\mathrm{L}$ direction and then it changes to elongated shape when test orientation is changed to 

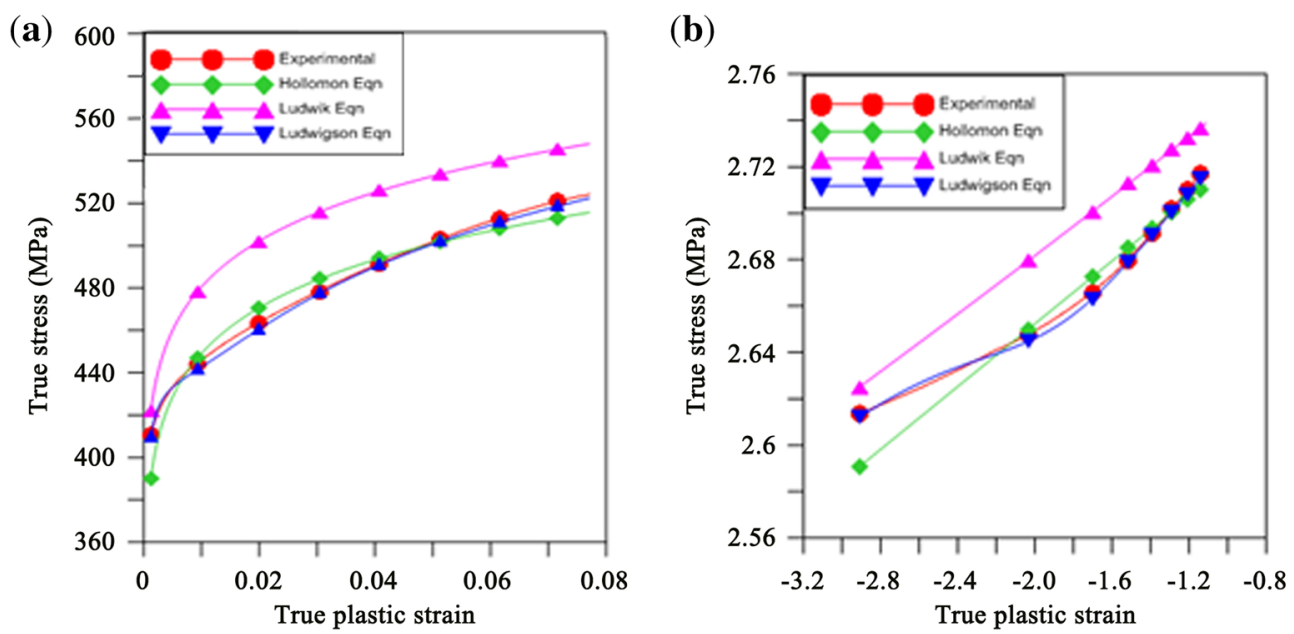

Figure 10. (a) True stress-true plastic strain data fitted using various flow relationships. (b) True stress-true plastic strain on log-log scale data fitted using various flow relationships.

Table 3. Anisotropy in tensile properties of aluminium alloy AA 2014 plate in peak-aged (ST $+450 \mathrm{~K} / 10 \mathrm{~h})$ treated condition.

\begin{tabular}{|c|c|c|c|c|}
\hline \multirow[b]{2}{*}{ Sl. no. } & \multirow[b]{2}{*}{ Property } & \multicolumn{3}{|c|}{ Specimen orientation with respect to the forging direction $\left({ }^{\circ}\right)$} \\
\hline & & $\mathrm{L}$ & $\mathrm{L}+45^{\circ}$ & $\mathrm{T}$ \\
\hline 1 & $0.2 \%$ Y.S. (MPa) & 450.1 & 422.0 & 447.2 \\
\hline 2 & UTS (MPa) & 496.4 & 472.8 & 492.3 \\
\hline 3 & Total elongation $(\%,(25 \mathrm{~mm}$ gauge length) & 11.04 & 5.32 & 8.92 \\
\hline 4 & Work-hardening exponent $n$ & 0.05678 & 0.04751 & 0.05013 \\
\hline 5 & $\sigma_{U T S /} \sigma_{Y}$ & 1.1026 & 1.1181 & 1.1169 \\
\hline 6 & $\begin{array}{l}\text { Hollomon equation } \\
\qquad \begin{array}{l}\sigma=k * \varepsilon_{p}^{n} \\
k \text { in MPa }\end{array}\end{array}$ & $\begin{array}{c}k=618.05 \\
n=0.05678\end{array}$ & $\begin{array}{c}k=578.94 \\
n=0.04751\end{array}$ & $\begin{array}{c}k=620.91 \\
n=0.05973\end{array}$ \\
\hline 7 & $\begin{array}{l}\text { Ludwik equation } \\
\sigma=\sigma_{0}+k_{1} * \varepsilon_{p}^{n 1} \\
\sigma_{0} \text { and } k_{1} \text { in } \mathrm{MPa}\end{array}$ & $\begin{array}{c}\sigma_{0}=298.6 \\
k_{1}=344.2 \\
n_{1}=0.1450\end{array}$ & $\begin{array}{c}\sigma_{0}=258.7 \\
k_{1}=331.8 \\
n_{1}=0.1097\end{array}$ & $\begin{array}{c}\sigma_{0}=312.3 \\
k_{1}=307.8 \\
n_{1}=0.1379\end{array}$ \\
\hline 8 & $\begin{array}{c}\text { Ludwigson equation } \\
\sigma=k_{1} * \varepsilon_{p}^{n 1}+\exp \left(k_{2}+\varepsilon_{p} * n_{2}\right) \\
k_{1} \text { and } k_{2} \text { in } \mathrm{MPa}\end{array}$ & $\begin{array}{c}k_{1}=630.57 \\
n_{1}=0.06368 \\
k_{2}=2.7874 \\
n_{2}=-125.85\end{array}$ & $\begin{array}{c}k_{1}=632.71 \\
n_{1}=0.07755 \\
k_{2}=3.7814 \\
n_{2}=-8.86\end{array}$ & $\begin{array}{c}k_{1}=670.08 \\
n_{1}=0.08532 \\
k_{2}=4.1524 \\
n_{2}=-105.38\end{array}$ \\
\hline
\end{tabular}

Tests were conducted at room temp at an initial strain rate of $10^{-4} \mathrm{~s}^{-1}$.

$\mathrm{L}+45^{\circ}$ and then to $\mathrm{T}$ direction (figure 9). The size of the dimples too gradually decreases from $\mathrm{L}$ to $\mathrm{T}$ test directions. This behaviour can be understood based on the growth of micro-voids and nucleation during tensile deformation, particularly in terms of the variation in $n_{1}$ and $n_{2}$ values. As analysed earlier, the higher degree of uniform elongation in $\mathrm{L}$ sample direction is associated with low nucleation and high growth of micro-voids. Consequently, elongation is

Table 4. Ludwigson flow curve parameters of solution-treated aluminium alloy AA 2014.

\begin{tabular}{|c|c|c|c|c|c|c|}
\hline Designation & $K_{1}(\mathrm{MPa})$ & $n_{1}$ & $K_{2}(\mathrm{MPa})$ & $-n_{2}$ & $\chi^{2}$ & $R^{2}$ \\
\hline Solution treated & 563.2 & 0.13245 & 3.1420 & 90.3519 & 1.43761 & 0.99586 \\
\hline Under-aged condition $(\mathrm{ST}+450 \mathrm{~K} / 2 \mathrm{~h})$ & 556.9 & 0.0686 & 3.0769 & 98.6940 & 1.74602 & 0.99474 \\
\hline Peak-aged condition $(\mathrm{ST}+450 \mathrm{~K} / 10 \mathrm{~h})$ & 670.1 & 0.08532 & 4.1524 & 105.37887 & 1.09095 & 0.99765 \\
\hline Overaged condition $(\mathrm{ST}+450 \mathrm{~K} / 20 \mathrm{~h})$ & 611.7 & 0.05869 & 4.1784 & 256.49874 & 5.83999 & 0.99592 \\
\hline
\end{tabular}



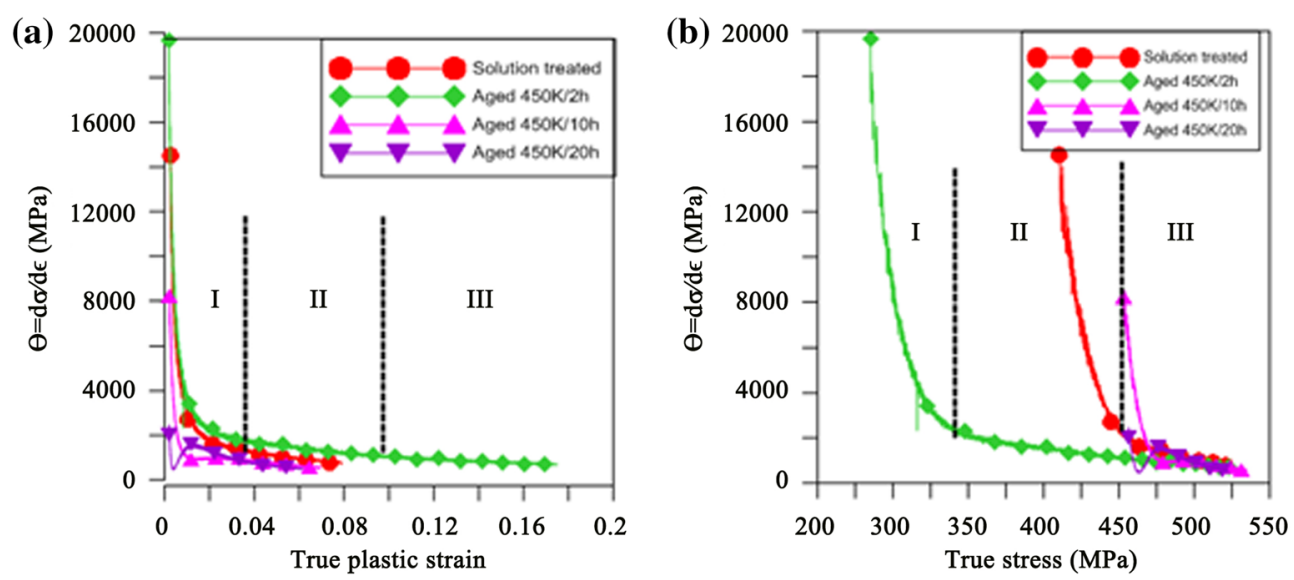

Figure 11. (a) Strain-hardening rate $\theta=(d \sigma / d \varepsilon)$ vs true plastic strain and (b) strain-hardening rate $\theta=(d \sigma / d \varepsilon)$ vs true stress of aluminium alloy AA 2014 sheet in various heat-treated conditions.
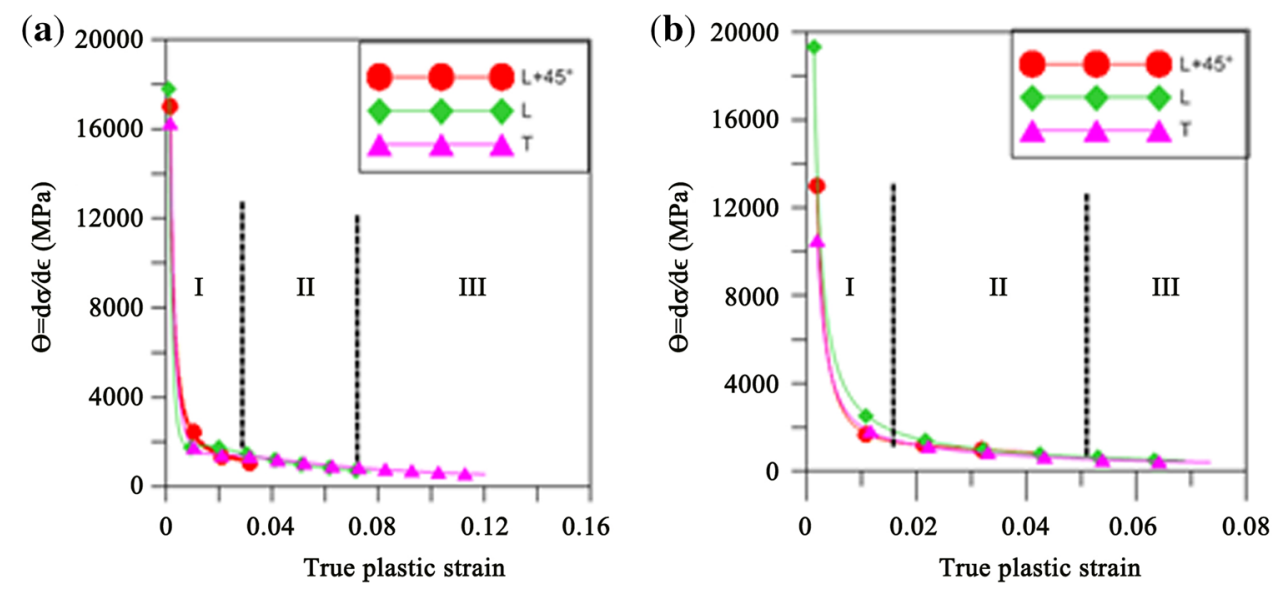

Figure 12. (a) Strain-hardening rate $\theta=(d \sigma / d \varepsilon)$ vs true plastic strain in solution-treated condition and (b) strain-hardening rate $\theta=(d \sigma / d \varepsilon)$ vs true plastic strain in peak-aged condition $(\mathrm{ST}+450 \mathrm{~K} / 10 \mathrm{~h})$, of aluminium alloy AA 2014 sheet in various specimen orientations.

Table 5. Values of $\chi^{2}$ obtained when experimental true stresstrue plastic strain data of aluminium alloy AA 2014 plates are fitted according to different flow relations.

\begin{tabular}{lllr}
\hline Heat treatment & Hollomon & Ludwik & Ludwigson \\
\hline $\begin{array}{l}\text { Solution treated } \\
\text { Under-aged condition } \\
\quad(\mathrm{ST}+450 \mathrm{~K} / 2 \mathrm{~h})\end{array}$ & 25.11365 & 1.62531 & 1.43761 \\
$\begin{array}{c}\text { Peak-aged condition } \\
\quad(\mathrm{ST}+450 \mathrm{~K} / 10 \mathrm{~h})\end{array}$ & 23.34670 & 2.7938 & 1.74602 \\
$\begin{array}{c}\text { Overaged condition } \\
\quad(\mathrm{ST}+450 \mathrm{~K} / 20 \mathrm{~h})\end{array}$ & 31.02800 & 3.65965 & 1.09095 \\
\hline
\end{tabular}

maximum along the $\mathrm{L}$ sample direction for peak-aged condition. The low ductility and lower values of $n_{1}$ in $\mathrm{L}+45^{\circ}$ direction also support the mechanism and formulation of McClintock [34]:

$$
\varepsilon_{f}=\frac{(1-n) \ln \left(1_{0} / 2 \mathrm{~b}_{0}\right)}{\sinh (1-n)\left(\sigma_{\mathrm{a}}+\sigma_{\mathrm{b}}\right) /(2 \sigma / \sqrt{3})}
$$

where $\varepsilon_{f}$ is the fracture strain of the material, $b_{0}$ is the radius of cylinder-shaped voids in material and $I_{0}$ is average spacing between voids with a power law stress-strain curve. In this equation the stresses parallel and perpendicular to the axis of cylindrical voids are represented by $\sigma_{a}$ and $\sigma_{b}$, respectively, and $\sigma$ is the true flow stress. Equation (4) shows that the increase in micro-void fraction is associated with the reduction in ductility as well as strainhardening exponent. This also reflects that the comparatively less uniform strains at tensile fracture along $\mathrm{L}+45^{\circ}$ sample directions are due to nucleated micro-voids of dissimilar nature, which cause difficulty in compatibility of deformation. 
Table 6. Flow parameters (in Ludwigson equation) of various FCC materials with different levels of stacking fault.

\begin{tabular}{|c|c|c|c|c|c|c|}
\hline Alloy & Stacking fault energy $\left(\mathrm{mJ} \mathrm{m}^{-2}\right)$ & $K_{1}(\mathrm{MPa})$ & $n_{1}$ & $K_{2}(\mathrm{MPa})$ & $n_{2}$ & $\varepsilon_{L}$ \\
\hline $\mathrm{Fe}-\mathrm{Ni}-\mathrm{Cr}-\mathrm{Al}$ alloy & NA & 1549 & 0.440 & 5.539 & -33.10 & 0.086 \\
\hline $17 \mathrm{Cr}-15 \mathrm{Mn}-0.4 \mathrm{~N}$ steel & NA & 1939 & 0.478 & 10.637 & -24.27 & 0.087 \\
\hline Stainless steel (T5482-1) & $\sim 20$ & 1359 & 0.507 & 9.996 & -17.47 & 0.154 \\
\hline Brass & $<10$ & 553 & 0.495 & 0.366 & -23.51 & 0.141 \\
\hline Silver & $\sim 25$ & 357 & 0.435 & 7.839 & -70.25 & 0.034 \\
\hline Copper & $\sim 80$ & 483 & 0.405 & 7.868 & -75.80 & 0.028 \\
\hline Nickel & $\sim 150$ & 1064 & 0.357 & - & - & - \\
\hline Aluminium & $\sim 200$ & 148 & 0.216 & - & - & - \\
\hline
\end{tabular}
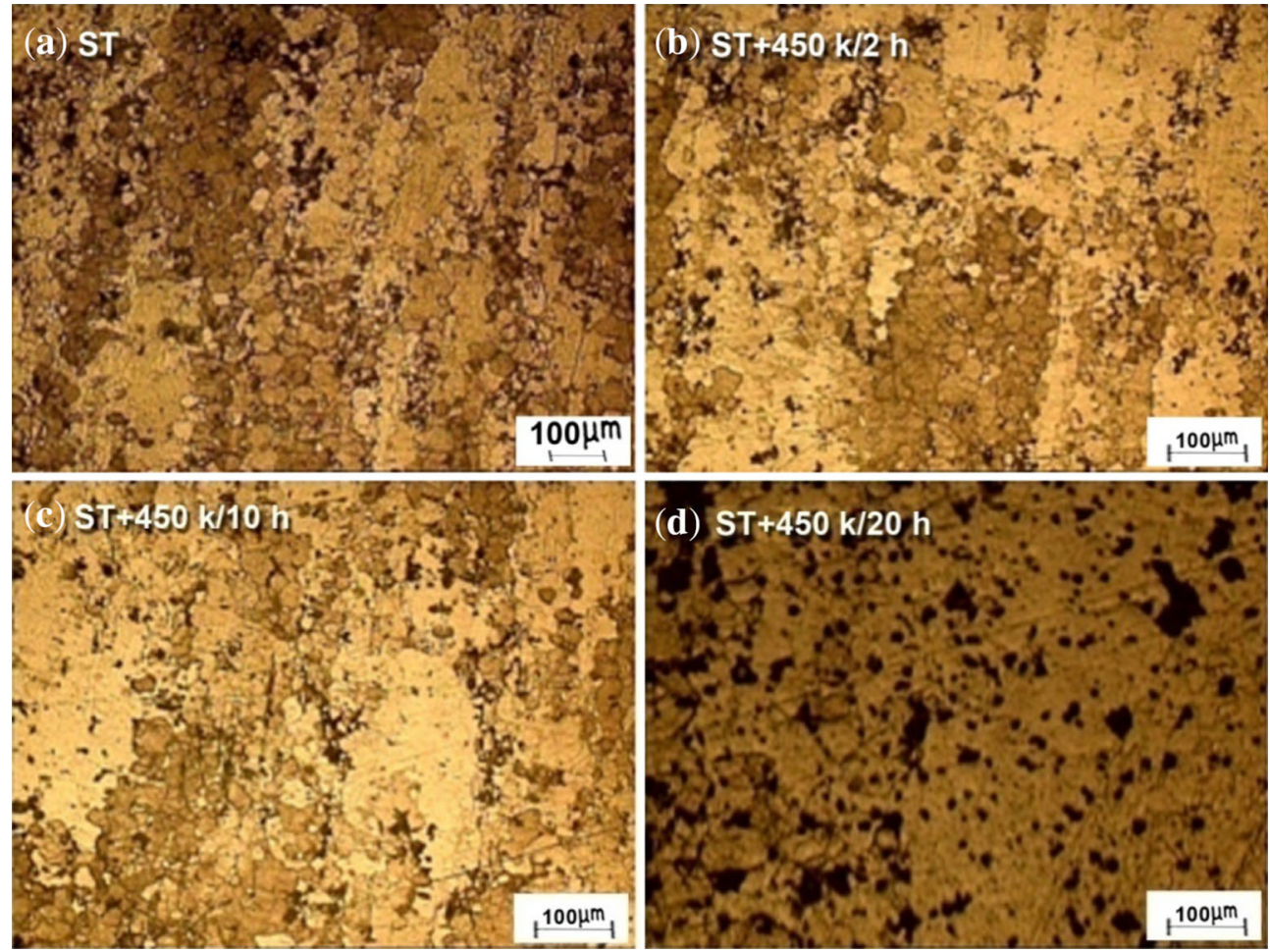

Figure 13. Optical micrographs showing microstructure of aluminium alloy AA 2014 alloy specimens after tensile deformation to fracture: (a) solution-treated condition, (b) aged at $450 \mathrm{~K}$ for $2 \mathrm{~h}$, (c) aged at $450 \mathrm{~K}$ for $10 \mathrm{~h}$ and (d) aged at $450 \mathrm{~K}$ for $20 \mathrm{~h}$.

Table 7. In-plane anisotropy $\left(A_{I P}\right)$ and anisotropic index $(\delta)$ of aluminium alloy AA 2014.

\begin{tabular}{cccc}
\hline $\begin{array}{l}\text { Sl. } \\
\text { no. }\end{array}$ & Condition & $\begin{array}{c}\text { In-plane anisotropy } \\
A_{I P}(\%)\end{array}$ & $\begin{array}{c}\text { Anisotropic } \\
\text { index } \delta\end{array}$ \\
\hline 1 & ST & -1.14 & 3.158 \\
2 & ST $+450 \mathrm{~K} /$ & -6.31 & 10.620 \\
& $10 \mathrm{~h}$ & & \\
\hline
\end{tabular}

\section{Conclusions}

1. Experimental engineering stress-engineering strain and true stress-true strain data of the aluminium alloy AA 2014 in solution-treated as well as aged conditions have been analysed using Hollomon, Ludwik and Ludwigson flow relationships. The Ludwigson relationship provides the best fit of data for all the conditions.

2. The highest strain-hardening rate is observed for the alloy specimen aged at $450 \mathrm{~K} / 2 \mathrm{~h}$ and the specimen aged at $450 \mathrm{~K} / 20 \mathrm{~h}$ exhibits the lowest strain-hardening rate.

3 . The current alloy exhibits moderate values of both inplane anisotropy $\left(A_{I P}\right)$ and anisotropic index $(\delta)$, which is attributed to the presence of anisotropy. In-plane anisotropy $\left(A_{I P}\right)$ and anisotropic index $(\delta)$ are the highest in peak-aged $(\mathrm{ST}+450 \mathrm{~K} / 10 \mathrm{~h})$ condition and moderate in solution-treated condition.

4. The transition in macroscopic flow behaviour of the alloy in solution-treated condition can be correlated to dislocation mechanism. Although ageing does not appear 
to alter the macroscopic flow behaviour, it causes considerable change in various flow parameters and sub-structural changes.

5. The fracture surface is fibrous and associated with elongated grains involved in failure at grain boundaries of solution-treated specimens. The dimples appear to be in two sizes (coarse and fine/micro-dimples); gross dimple fracture could have resulted from the coalescence, void-nucleation and growth. The void-nucleation particles presumably are large sized insoluble dispersoids.

\section{Acknowledgements}

The authors thank SAIF, IIT Bombay, for the permission in utilising the facility of SEM. The authors also thank RCMA, DRDO, Hyderabad, for heat treatment, optical microscopy and hardness testing and AMTL, Hyderabad, for tensile testing. One of the authors ( $G$ Narender) gratefully acknowledges Dr K Chandra Shekar for his help and encouragement.

\section{References}

[1] Abood A N, Saleh A H and Abdullah Z W 1993 Effect of heat treatment on strain life of aluminium alloy AA6061. $J$. Mater. Sci. Res. 2: 51-59

[2] Cai C, Ji Z, Zhang H and Wang G 2009 Study on microstructure and texture of 3003 aluminum sheets rolled by laser textured roll. J. Metall. 9: 1-6

[3] Venkateshwarlu G, Davidson M J and Tagore G R N 2010 Finite element simulation of deep drawing of aluminium alloy sheets at elevated temperatures. ARPN J. Eng. Appl. Sci. 5: 1-6

[4] Reid R J, Jones A H and Green S J 1974 Characterization of 2014-T651 aluminium alloy. Army Materials and Mechanics Research Centre

[5] Siegert K and Wagner S 1994 Formability characteristics of aluminium sheet. TALAT Lecture 3701, European Aluminium Association

[6] Ankamma K, Ravindra Reddy P V R, Eswara Prasad N, Nagarjuna S, Chandra Mohan Reddy G and Komaraiah M 2011 Numerical simulation for the determination of the limit drawing ratio of a cold rolled and solution treated Nimonic C-263 alloy sheet. Trans. Indian Inst. Met. 102: 323-330

[7] Ankamma K, Satyanarayana D V V, Prasad K S, Chandramohan Reddy G, Komaraiah M and Eswara Prasad N 2011 Effects of aging and sheet thickness on the room temperature deformation behaviour and in-plane anisotropy of cold rolled and solution treated Nimonic C-263 alloy sheet. Int. J. Mater. Res. 102: 1274-1285

[8] Ankamma K, Singh A K, Prasad K S, Eswara Prasad N and Chandra Mohan Reddy G 2014 Yield locus of a cold rolled and solution treated Nimonic-263 alloy sheet, determined using asymmetrical Knoop microhardness indenter. Trans. Indian Inst. Met. 67: 531-539
[9] Eswara Prasad N and Malakondaiah G 1992 Anisotropy of mechanical properties in quaternary $\mathrm{Al}-\mathrm{Li}-\mathrm{Cu}-\mathrm{Mg}$ alloys. Bull. Mater. Sci. 15: 297-310

[10] Eswara Prasad N 1993 In-plane anisotropy in the fatigue and fracture properties of quaternary $\mathrm{Al}-\mathrm{Li}-\mathrm{Cu}-\mathrm{Mg}$ alloys. Doctoral Thesis, Banaras Hindu University Varanasi, India

[11] Eswara Prasad N, Kamat S V, Prasad K S, Malakondaiah G and Kutumbarao V V 1993 In-plane anisotropy in fracture toughness of Al-Li 8090 plate. Eng. Fract. Mech. 46: 209-223

[12] Eswara Prasad N, Malakondaiah G, Kutumbarao V V and Rama Rao P 1996 In-plane anisotropy in low cycle fatigue properties of and bilinearity in Coffin-Manson plots for quaternary Al-Li-Cu-Mg 8090 alloy plate. Mater. Sci. Technol. 12: 563-577

[13] Jata K V, Hopkins A K and Rioja R 1996 The anisotropy and texture of Al-Li alloys. Mater. Sci. Forum 217: 647-652

[14] Jata K V, Panchanadeeswaran S and Vasudevan A K 1998 Evolution of texture, microstructure and mechanical property anisotropy in an Al-Li-Cu alloy. Mater. Sci. Eng. A 257: 37-46

[15] Mehta K K, Mukhopadhyay P, Mandal R K and Singh A K 2014 Mechanical properties anisotropy of cold rolled and solution-annealed Ni-based hastalloy C-276. Metall. Mater. Trans. 45: 3493-3514

[16] ASTM Standard E-8 2013 Standard test methods for tension testing of metallic materials. West Conshohocken, PA: ASTM International

[17] Banumathy S, Mandal R K and Singh A K 2011 Hot rolling of binary $\mathrm{Ti}-\mathrm{Nb}$ alloys part-II: mechanical properties anisotropy. Int. J. Mater. Res. 102: 208-217

[18] Eswara Prasad N, Prasad K S, Kamat S V and Malakondaiah G 1995 Influence of microstructural features on the fracture resistance of aluminium lithium alloy sheets. Eng. Fract. Mech. 51: 87-96

[19] Hales S J and Hafley R A 1998 Texture and anisotropy in AlLi alloy 2195 plate and near-net-shape extrusion. Mater. Sci. Eng. A 257: 153-164

[20] Rioja R J and Liu J 2012 The evolution of Al-Li base products for aerospace and space applications. Metall. Mater. Trans. A 43: 3325-3337

[21] Wu Y T and Koo C H 1998 Effect of temperature on the anisotropic super plasticity of textured $\mathrm{Ti}-25 \mathrm{Al}-10 \mathrm{Nb}$ alloy. Scr. Metall. 38: 267-271

[22] Lavakumar A, Murthy C H V S, Satyanarayana D V V and Eswara Prasad N 2013 Strain hardening behaviour of a nickel based superalloy supercast 247A. Int. J. Sci. Eng. Res. 4: 1914-1920

[23] Duesbery M S and Vitek V 1998 Plastic anisotropy in B.C.C. transition metals. Acta Mater. 46: 1481-1492

[24] Ludwigson D C 1971 Modified stress-strain relations for FCC metals and alloys. Metall. Trans. 2: 2825-2828

[25] Satyanarayana D V V, Satya Prasad K, Malakondaiah G and Sarma D S 2007 Strain hardening behaviour of an $\mathrm{Fe}-\mathrm{Ni}-$ Cr-Al alloy. Mater. Sci. Technol. 23: 79-86

[26] Asagari S, El-Danaf E, Kalidindi S R and Doherty R D 1997 Strain hardening regimes and microstructural evaluation during large strain compression of low stalking fault energy FCC alloys that form deformation twins. Metall. Mater. Trans. 28: 1781-1795 
[27] Barlat F and Lian K 1989 Plastic behaviour and stretchability of sheet metals. Part I: A yield function for orthotropic sheets under plane stress conditions. Int. J. Plasticity 5: 51-66

[28] Doorbar P J, Borradaile B and Driver D 1986 Evaluation of aluminium-lithium-copper-magnesium-zirconium alloy as forging material. In: Proceedings of the 3rd International Conference on Aluminium-Lithium Alloys, Institute of Metals, London, pp. 496-508

[29] Lee E W and Kim N J 1989 Proceedings of the 5th International Al-Li Conference, vol. 2, pp. 809-815

[30] Mondal C, Singh A K, Mukhopadhyay A K and Chattopadhyay K 2012 Mechanical property anisotropy of 7010 aluminium alloy sheet having single rotated-brass texture. Mater. Sci. Forum 702: 303-306
[31] Tempus G, Calles W and Scharf G 1991 Influence of extrusion process parameters and texture on mechanical properties of Al-Li extrusions. Mater. Sci. Technol. 7: 937-945

[32] Mishra S, Kulkarni K and Gurao N P 2015 Effect of crystallographic texture on precipitation induced anisotropy in an aluminium magnesium silicon alloy. Mater. Des. 87: 507-519

[33] Mishra S, Yadava M, Kulkarni K and Gurao N P 2017 A modified Taylor model for predicting yield strength anisotropy in age hardenable aluminium alloys. Mater. Sci. Eng. A 699: 217-228

[34] McClintock F A 1968 A criterion of ductile fracture by the growth of holes. J. Appl. Mech. 35: 363-371 